\title{
Article \\ A High-Fidelity Modelling Method for Mine Haul Truck Dumping Process
}

\author{
Aaron Young * (D) and William Pratt Rogers
}

Department of Mining Engineering, University of Utah, Salt Lake City, UT 84112, USA; pratt.rogers@utah.edu

* Correspondence: aaron.s.young@utah.edu

\begin{abstract}
Dumping is one of the main unit operations of mining. Notwithstanding a long history of using large rear dump trucks in mining, little knowledge exists on the cascading behavior of the runof-mine material during and after dumping. In order to better investigate this behavior, a method for generating high fidelity models (HFMs) of dump profiles was devised and investigated. This method involved using unmanned aerial vehicles with mounted cameras to generate photogrammetric models of dumps. Twenty-eight dump profiles were created from twenty-three drone flights. Their characteristics were presented and summarized. Four types of dump profiles were observed to exist. Factors that influence the determination of these profiles include the location of the truck relative to the dump crest, the movement of the underlying dump material during the dumping process and the differences in the dump profile prior to dumping. The HFMs created in this study could possibly be used for calibrating computer simulations of dumps to better match reality.
\end{abstract}

Keywords: dumping; digital transformation; high-fidelity modelling

check for

updates

Citation: Young, A.; Rogers, W.P. A High-Fidelity Modelling Method for Mine Haul Truck Dumping Process. Mining 2022, 2, 86-102. https:// doi.org/10.3390/mining2010006

Academic Editors: Juan M MenéndezAguado, Oscar Jaime Restrepo Baena and Jessica M. Smith

Received: 17 December 2021

Accepted: 4 February 2022

Published: 11 February 2022

Publisher's Note: MDPI stays neutral with regard to jurisdictional claims in published maps and institutional affiliations.

Copyright: (C) 2022 by the authors. Licensee MDPI, Basel, Switzerland. This article is an open access article distributed under the terms and conditions of the Creative Commons Attribution (CC BY) license (https:// creativecommons.org/licenses/by/ $4.0 /)$.

\section{Introduction}

Mine-to-mill optimization is a longstanding goal of the mining industry [1-4]. This approach focuses on optimizing the entire process around run-of-mine (ROM) material characteristics, rather than optimizing the unit operations to material characteristics individually. The primary motivation for this approach is ensuring that the priority for optimization is given to the most demanding and costly process (grinding) [5]. Despite its success, one difficulty in holistic mine-to-mill optimization stems from a lack of understanding around material behavior during and between unit operations [4].

Unit operations are defined within the context of mining as the basic steps used to produce mineral value from a deposit. They generally fall into either the category of rock fragmentation or materials handling [6]. Materials handling, for surface truck and shovel mines, comprises three steps, known as loading, hauling and dumping. Dumping commonly consists of the haul truck spotting itself into position and dropping ROM material from the back. This material forms a small heap if it is dumped on a flat surface, or cascades along the edge of a dump face if dumped over a developing dump, stockpile or dump/heap leach [7]. While there are minor differences in each of these earthworks, for the simplification of this article, they are referred to as rock piles [8].

Notwithstanding a long history of using large rear dump trucks in mining, little knowledge exists on the cascading behavior of ROM material during and after dumping. At least two schools of thought comprise the knowledge that does exist. The first school of thought studies ROM cascading behavior from an external perspective. The second seeks to understand the smorgasbord of characteristic properties that govern this behavior internally. Since this paper focuses primarily on the external viewpoint, only a sample of the literature pertaining to the internal philosophy is presented in order to call attention to some of its challenges. McLemore et al. [8] provide a robust review that includes a trove of references from each school of thought, should readers wish to dive deeper. 
Work related to factors that influence ROM material behavior from an internal philosophy are numerous, and a complete review of their literature is not within the scope of this paper. A plethora of material property variables relate to these factors, which include shear strength, bulk density, particle size and shape distribution, cohesive properties, friction angle, moisture content, etc. [8,9]. Several issues confound the ability to fully isolate and understand these variables. First, the size, shape and variability of the ROM material are greatly dependent on blasting, which is not yet a fully understood process $[10,11]$. Second, the successful testing of material property variables depends heavily on sampling and statistical estimation [12]. Furthermore, dump faces are hazardous, and observation of the dumping process is challenging [13]. Additionally, dozers and other equipment handle the material subsequent to dumping, which compound with the issues mentioned previously [7]. Moreover, some complex engineering issues, such as reclamation and slope stability, are commonly considered to be linked to factors involving these material property variables in ways not fully understood, which increases the debate related to them [13-15]. Mines may also be under the assumption that understanding these factors must originate from a first-principles approach, rather than a data-driven statistical and mathematical approach [16].

Traditional viewpoints and operational strategies within the mining industry generally hinder innovation $[17,18]$. This might be particularly true for each of the three kinds of rock piles. Stockpiles have been seen as only useful to mines as a buffer against production variability [19-21]. Dump/heap leach design optimization involves many meticulous considerations that take precedence over understanding the minutia of the dumping process, which may be considered to be optimized under simple guidelines [22]. Waste dumps have been reserved for material below the economic cut-off grade and, as a result, have historically been given little attention beyond safety and risk management [23]. While these traditional viewpoints would need to change in order for rock pile innovation to be successful, they need only be challenged in order for research in these areas to be justified.

Literature and news articles provide both cases and causes for some changing perspectives that motivate and support the endeavor of this paper. First, even though the primary function of stockpiles remains the same [24], COVID-19 and global supply chain disruptions have placed increased demand on their use [25-34]. Increased knowledge of stockpile assets as the result of understanding the dumping process might afford mining companies a competitive edge in a post-pandemic world [35-38]. Second, while much of the seminal work in heap leach modelling involved small laboratory column studies operating at the particle scale [39-41], there has been a recent shift towards modelling bulk scale phenomena (inter-/intra-particle diffusion, liquid holdup and hysteresis, gas flow, etc. $[42,43])$ as well as understanding the factors more closely correlated with the dumping process (stratification, segregation, breakage induced by ore stacking, etc. [44-46]). It is true that a better understanding of the dumping process will likely not lead to changes in the construction of heap leaches. However, it may yield an understanding of the gestalts about the bulk phenomena in existing heap leaches, and aid in the development of models that increase their profitability [47]. Third, what was once considered to be below cut-off grade may later become mineable ore [48-52]. Therefore, a deeper understanding of the dumping process as it relates to waste dumps may prove valuable for operations, where old waste dumps become economically viable [53-56]. Finally, the perfunctory amount of documented work, aimed at capitalizing on the opportunities hypothesized previously, may have less to do with the merit of such hypotheses, and more to do with the mining sector's lag in innovation $[17,18,57]$.

To improve the understanding of end-dumping and rock pile construction, we present a method for creating a high-fidelity model (HFM) of the dumping process through a digital transformation approach. Digital transformation [57,58], employs an external philosophy for understanding ROM behavior, and is a process whereby real-world assets and processes are digitally transformed in ways that add value for decision makers. Innovation [59] and emerging technologies [60] make digital transformation possible. Unmanned aerial 
vehicles (UAVs), also known as drones, are an emerging technology [61] that allows for the digital transformation of the dumping process through data collection. Rock pile faces span large areas, and the nature of the material requires multiple vantage points for sensors or traditional surveys to be effective. By using photogrammetry, UAVs are capable of capturing multiple angles and covering large difficult areas, such as a dump face [47,62]. Thus, an investigation into whether photogrammetry can create the HFM of an individual truck end dump is of interest to the issue of better understanding the dumping process and rock pile construction.

HFMs act as reference systems to reality [63]. These models are commonly used in engineering to calibrate simulation models [64] where there is a need to rapidly prototype many different design permutations [65], or where measuring the real data being modelled is not practical [66]. HFMs are modular elements, and HFM integration is a modular framework that allows each aspect of the full model to be worked on independently [67]. This modularity means that simulations to match HFMs can be worked on independently from the work used to improve how HFMs match with reality.

Digital transformation techniques are fairly new, and little work has been conducted to digitally transform the process of rock pile construction via haul truck end-dumping. Zahl et al. [9] accurately assert that the formation and shape of mine rock piles are based mainly on topography. While this work is foundational to the engineering of rock pile construction, it offers little for the purposes of rock pile digital transformation. Mclemore et al. [8] provide an extensive review on the construction, the factors influencing the shear strength of soil, characterization, the effects of weathering and the stability of rock piles throughout the world. Their review is more informative than that of Zahl et al.; however, it likewise does not consider a digital approach. Zhao [68] developed a real-time 3D modelling and mapping technique for the stockpiles formed by stacking/reclaiming machines for iron ore. Zhao's work is pioneering in the area of the digital transformation of small, intermediary stockpile construction, but does not consider the large rock fills made by haul truck enddumping. The authors of this present paper previously illustrated a method for modelling and mapping large heap-filled stockpiles using fleet management system (FMS) data [7]. However, while these data were amicable to modelling, no external data were available for the validation of the model. Zhang and Liu [47] employed UAV aerial photography and performed image analysis to investigate particle size distribution along the face of a dump leach. However, while they demonstrated the ability of UAV aerial photography to capture relevant data, they did not capture the volumes of individual dump profiles that could be used as a baseline to digitally transform the end-dumping rock pile construction process. Servin et al. [4] present a digital transformation technique for holistic mine-to-mill distributed particle simulation where the gaps between unit operations are simulated using data from control systems and sensors. While other frameworks for similar integration have been proposed in the past, the focus Servin et al. place on a unit operation-centered framework is consistent with the aims of this paper and the future direction of research in this area.

The method presented in this work demonstrates how to create 3D HFMs of ROM end-dumping from photogrammetry. The method presented is very similar to that of Zhang and Liu [47]. The resulting HFMs are akin to the model developed by Zhao [68], only they involve end-dumped rock piles as opposed to stacker-made intermediary stockpiles. These HFMs could be potentially suitable for the technique presented by Servin et al. [4] for holistic mine-to-mill optimization, which includes large end-dumped rock piles. They may also be used as a modular test bed for the calibration of future simulations of mine haul truck dumping activity. The end goal of the HFMs this method creates is the parameterization of dumping as a unit operation process. Essentially, while the foundational work of Zahl et al. [9] explains that topography is the main factor influencing rock pile shape, the method presented in this paper may be used to increase our understanding of the expected variability and parameters in such topography common to the end-dumping and rock 
pile construction process, thereby making these shapes more predictable and amicable to modelling.

\section{Materials and Methods}

\subsection{Material and Haulage Equipement}

The material studied was low-grade run-of-mine (ROM) gold ore from a surface mining operation near Perth, WA. No additional characterization of the material is required for presenting the concept of this method, although future simulation and modelling work will require more detailed characterization in order to ensure that models are properly calibrated.

The ore was transported and dumped using CAT 793F haul trucks with a payload of approximately 231 metric tons, a struck capacity of $112.6-151 \mathrm{~m}^{3}$ and an inside bed width of $7334 \mathrm{~mm}$.

\subsection{UAV Flights and Photogrammetry Methodology}

Field work and UAV flights were conducted in coordination with the mine's survey crew and through the use of their equipment. A total of 23 flights were recorded over the course of five day-shifts. These flights were performed using a DJI Matrice M200 drone with a Zenmuse X5S camera (DJI-Innovations Company Limited, Shenzhen, China). Table 1 shows details about the camera and flight settings used in these flights.

Table 1. Camera and Flight Details.

\begin{tabular}{|c|c|c|c|c|c|c|c|}
\hline \multicolumn{4}{|c|}{ Camera Details } & \multicolumn{4}{|c|}{ Flight Details } \\
\hline Sensor Type & $\begin{array}{c}\text { Sensor Size } \\
(\mathrm{mm})\end{array}$ & $\begin{array}{c}\text { Focal Length } \\
(\mathrm{mm})\end{array}$ & $\begin{array}{c}\text { Image Size } \\
\text { (Pixels) }\end{array}$ & $\begin{array}{c}\text { Flight Height } \\
\text { (m) }\end{array}$ & $\begin{array}{c}\text { Average Flight } \\
\text { Area }\left(\mathrm{m}^{2}\right)\end{array}$ & $\begin{array}{c}\text { Average } \\
\text { Photos Taken }\end{array}$ & Flight Style \\
\hline M4/3 CMOS & $12.8 \times 8.6$ & 8.6 & $5472 \times 3648$ & 60 & 74,500 & 65 & Snaking Grid \\
\hline
\end{tabular}

The methodology for the flights was as follows:

1. An initial flight was performed to create and update the local orthomosaic map (approximately $6 \mathrm{~min}$ );

2. Ground control points (GCPs) were marked and surveyed (3 to 7 GCPs were used for each flight);

3. A second flight was performed with an adjusted flight path to include ground control points (approximately $7 \mathrm{~min}$ );

4. A Quick Map was created from the second adjusted flight path so that the area of interest (dump area) could be readied, and the working flight path programmed;

5. Once steps 1 through 4 were completed, flights were repeated using the site scan Quick Fly software function in the same area along the same flight path to capture the dump face during different time intervals and thereby capture before and after photos of the dumping process during regular operation $(60 \mathrm{~m}$ flight height, $6 \mathrm{~min}$ flight times).

Once the flights were completed, pictures were uploaded to the 3DR cloud processing system, and photogrammetric point clouds were generated from the flight photos using Pix4D software (mapper 4.1 version, Pix4D SA, Lausanne, Switzerland). Absolute and relative accuracy were calculated for each GCP in the $\mathrm{X}, \mathrm{Y}$ and $\mathrm{Z}$ coordinate directions. These calculations were performed automatically as part of the 3DR cloud processing.

Figure 1 shows a top view (XY plane) of an example flight plan with GCP locations and the corresponding image overlap map generated from the flight. All flight plans were similar to Figure 1, with the only changes being the location of different GCPs. The thick black curved line in Figure 1 represents the upper crest of the dumping area, and it is a close approximation to the actual dump crest. As demonstrated by Figure 1, the dump crest area for each flight was photographed with 5 or more images of overlap. 




Figure 1. Top (XY Plane) view of a typical flight plan. Stars represent locations of ground control points (GCPs). The dashed line shows the flight path of the UAV. The shaded area is an approximation of the dump area. The color represents the number of overlapping images in accordance with the scale shown.

\subsection{Point Cloud Analysis}

Maptek $^{\mathrm{TM}}$ PointStudio (2021.1 version, Maptek/KRJA Systems Inc, Golden, Colorado, USA) was used to model and analyze the resulting point cloud data. These data were imported as individual files and converted into triangulation solids. Then, they were 
analyzed for overlapping areas where dumps had occurred. Polygons were created around the dump areas, and the two triangulations were processed into extracted solids. These extracted solids are considered to be 3D volumetric HFMs of individual haul truck dump profiles within the simulation and modelling context described in the introduction. The reason these software tools, as well as the drone equipment, were used is because they were what was available and provided by the mine. The results section details the HFMs created by this study. All HFM files are available at the link, https: / / zenodo.org/record/ 5789951\#.YgQiqJbMKU1.

\subsection{Classification Method}

Little taxonomic terminology yet exists for the information presented in this article. Classification involved qualitative analysis by the authors on the HFMs, with an emphasis on attributes hypothesized to be of interest to characterizing the final position and geometry of the dump profile. From the qualitative analysis, the categories and characteristics of the dumps were created, and each dump was assigned to the matching category. Data on the resulting classification are presented along with the statistical information of each category.

\section{Results}

\subsection{UAV Flights and Field Work Results}

Tables 2 and 3 show the root mean square (RMS) error values and the ground sampling distance (GSD) of the models computed from the drone flight data, respectively. Errors between the modelled coordinates of a GCP and its known survey coordinates are frequently used to represent the accuracy of a photogrammetry model [69].

Table 2. RMS Error Values by Coordinate Direction.

\begin{tabular}{ccccccccc}
\hline \multirow{2}{*}{$\begin{array}{c}\text { Coordinate } \\
\text { Direction }\end{array}$} & Minimum & Average & Maximum & $\begin{array}{c}\text { Standard } \\
\text { Deviation }\end{array}$ & Minimum & Average & Maximum & $\begin{array}{c}\text { Standard } \\
\text { Deviation }\end{array}$ \\
\cline { 2 - 9 }$y$ & 0.000565 & 0.011916 & 0.03008 & 0.008417 & 0.684995 & 2.410617 & 3.931733 & 0.790573 \\
\hline X & 0.000574 & 0.009329 & 0.032239 & 0.008137 & 1.128254 & 2.119136 & 3.641948 & 0.610887 \\
\hline $\mathrm{Z}$ & 0.001044 & 0.017912 & 0.046895 & 0.011906 & 0.881072 & 7.083288 & 15.086508 & 4.262623 \\
\hline
\end{tabular}

Table 3. GSD Values of the Photogrammetry Models.

\begin{tabular}{cccc}
\hline \multicolumn{4}{c}{ GSD Values (cm/pixel) } \\
\hline Minimum & Average & Maximum & Standard Deviation \\
\hline 1.72 & 2.2 & 2.52 & 0.26 \\
\hline
\end{tabular}

RMS errors represent the quadratic means of these errors in the $\mathrm{X}, \mathrm{Y}$ and $\mathrm{Z}$ coordinate directions. Both absolute and relative RMS error values are given. Absolute error represents the error in the coordinate location of the GCPs to their actual location on earth. Relative error represents the error in coordinate location of the GCPs as they relate to each other. Relative error is of more interest to this study, since the integrity of the HFMs is reliant on achieving a low relative error in the photogrammetry models.

Low ground sampling distance (GSD) values are required for accurate photogrammetry [69]. GSD is the physical distance represented between the centers of two adjacent pixels, and it can be estimated in advance of a flight based on the camera and flight details. With the drone flying at a $60 \mathrm{~m}$ height, a GSD of $1.64 \mathrm{~cm} / \mathrm{pixel}$ is considered to be the lowest possible GSD value based on the camera specifications. Slight deviations due to perspective, the vibrations of the camera, blur, depth of field and other factors lead to variations in GSD at every point of a photogrammetric model. The GSD values calculated for the photogrammetry models of this study can be found in Table 3 . 
In Tables 2 and 3, the accuracy of the photogrammetry models is given. These accuracy values are important to consider, since they determine the granularity of the HFM models. The accuracy error of a given model will be at least the GSD value in each coordinate direction. Considering that the highest average GSD value of all flights was $2.52 \mathrm{~cm} / \mathrm{pixel}$, an accuracy error of at least $16 \mathrm{~cm}^{3}(2.52 \mathrm{~cm} \times 2.52 \mathrm{~cm} \times 2.52 \mathrm{~cm})$ to the volume of the HFM is expected to exist. Another way to confirm these accuracy errors is to multiply the RMS errors (Table 2) for each coordinate direction. The multiplication of the maximum relative errors for each coordinate direction, as shown in Table 2, gives $45.48 \mathrm{~cm}^{3}$, which is roughly 2.8 times the accuracy error obtained by cubing the GSD. This discrepancy is consistent with other photogrammetry models that have been correctly scaled and reconstructed, which typically contain accuracy errors between one to three times that of the GSD value. In summary, the accuracy of the volumes generated from the photogrammetry models used in this study can generally be considered to be accurate to within $50 \mathrm{~cm}^{3}$.

\subsection{Point Cloud Analyses and Results}

Of the 23 flights flown, 14 solids were extracted, from which 29 dump activities were identified and 28 were considered useable HFMs of the dumping process. Of these $28 \mathrm{HFMs}$, four types of dump profiles were determined to exist. The four dump types are named after their shape, as follows:
A. Oval,
B. Comet,
C. Rectangular,
D. Sloughed Heap.

Oval-type dump profiles are the most commonly occurring type of dump profile. These dump profiles are characterized by their oval shape when viewed from a vantage point normal to the dump face. These dumps have narrow ends at the crest and toe of the dump face, and a maximum width midway through the dump face. Comet dump profiles are characterized by a large volume near the base of the dump and a narrow trail of material extending upwards along the dump face. Rectangular dump profiles cover the entire dump face (or a large portion of it) evenly to a uniform width. Sloughed heap profiles occur when a portion of the material is not dumped over the edge of the berm, but rather on the floor of the upper level of the dump. This causes a portion of the material to bunch near the dump berm, and a part of it to slough over the edge of the dump.

Table 4 shows example grayscale renderings of what is observed in PointStudio for each of the four types of dumping profiles determined by a qualitative analysis of the dump HFMs. These example grayscale renderings are showcased via both front and side views. The front view shows the perspective facing the dump and in-line/parallel to the dump, with the dumping process proceeding from top to bottom. The side view represents the perspective perpendicular to the front view, with the dumping direction proceeding from top right to bottom left. Measurements of these profiles were performed using software functions found within PointStudio.

The HFM solids created in PointStudio were classified using the following variables: volume (in cubic meters), maximum height, length, width and thickness (in meters) and angle (in degrees) from bottom left to top right. Volume was determined by querying the properties of the HFM solids after their creation. Maximum height and maximum length were considered to be the vertical and horizontal legs of the right triangle formed by connecting the bottom left and top right points of the HFM solid. Maximum width was considered to be the distance between the two farthest horizontal points of the HFM solid from the front-view perspective. Thickness was considered to be the distance between the two farthest horizontal points of the HFM solid from the side-view perspective. Angle was considered to be the inner angle of the right triangle formed by connecting the bottom-left and top-right points of the HFM solid. These measurements are tabulated in Table 5. An additional visualization of the HFMs data containing all of the extracted solids is available 
in the data cache associated with this article. The link accessed to this data can be found in the "Supplementary Materials" section.

In total, 28 dumps were profiled and classified via qualitative analysis. Table 5 shows information from all of the dump profiles. With the exception of dumps 1, 2 and 3, all dumps were along the edge of a $30 \mathrm{~m}$ high dump crest. Table 5 reveals that large volume does not always indicate large maximum width, height or length. High angles do not indicate large volume, but seem to increase the maximum width, height or length. In the case of sloughed heaps, the low angle is due to the fact that it is not measuring to the top of the berm, but to the extent of the dump profile, which occurs on the floor of the upper level of the dump area.

Table 4. Example front and side views of grayscale renderings of the HFM solids created in PointStudio for each of the four dump profile types.

\begin{tabular}{ccc}
\hline Dump Profile Type & $\begin{array}{c}\text { Front View } \\
\text { (Direction of Dumping } \downarrow \text { ) }\end{array}$ & $\begin{array}{c}\text { Side View } \\
\text { (Direction of Dumping } \leftarrow \text { ) }\end{array}$ \\
\hline Oval & & \\
$10 \mathrm{~m}$ & &
\end{tabular}

Comet
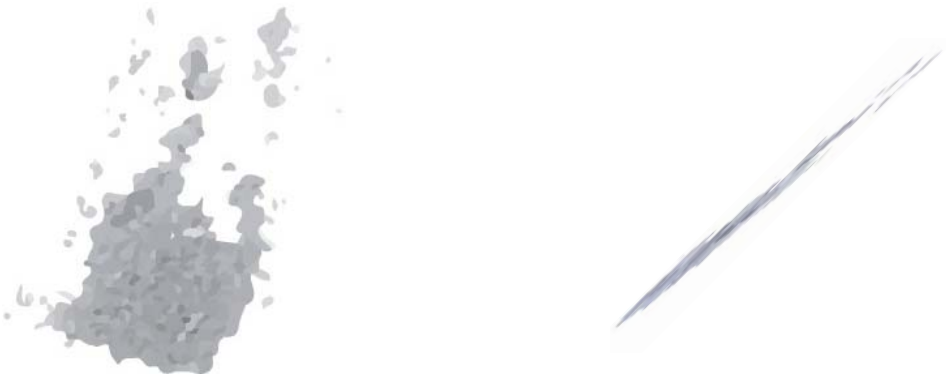

Rectangular

$10 \mathrm{~m}$
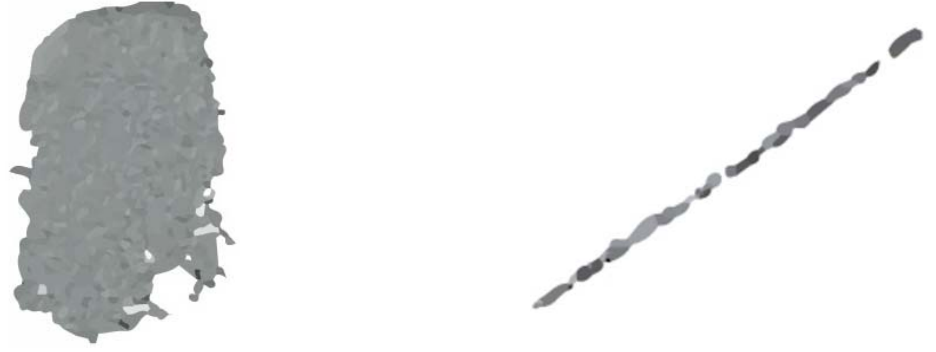

Sloughed Heap

Table 5. Summary of Classification Data for All Dump Profiles.

\begin{tabular}{|c|c|c|c|c|c|c|c|}
\hline Dump & Volume $\left(\mathrm{m}^{3}\right)$ & Max. Width (m) & Max. Height (m) & Max. Length (m) & Angle $\left(^{\circ}\right)$ & $\begin{array}{c}\text { Max. } \\
\text { Thickness (m) }\end{array}$ & Shape \\
\hline $1^{2}$ & 131 & 15 & 15 & 23 & 33 & 1.187 & Oval \\
\hline $2^{2}$ & $125^{1}$ & 12 & 16 & 25 & 31 & 0.957 & Rectangular \\
\hline $3^{2}$ & $125^{1}$ & 14 & 16 & 25 & 31 & 0.893 & Rectangular \\
\hline 4 & $121^{1}$ & 11 & 16 & 29 & 28 & 1.431 & Sloughed Heap \\
\hline 5 & $121^{1}$ & 14 & 30 & 44 & 36 & 0.368 & Oval \\
\hline 6 & $121^{1}$ & 13 & 31 & 43 & 36 & 1.207 & Oval \\
\hline 7 & 155 & 20 & 20 & 32 & 33 & 1.016 & Comet \\
\hline 8 & $119^{1}$ & 22 & 26 & 39 & 34 & 1.123 & Comet \\
\hline 9 & $119^{1}$ & 17 & 18 & 26 & 35 & 1.256 & Comet \\
\hline 10 & $119^{1}$ & 11 & 32 & 46 & 34 & 1.006 & Oval \\
\hline 11 & 134 & 20 & 28 & 40 & 35 & 0.887 & Oval \\
\hline 12 & $125^{1}$ & 15 & 21 & 35 & 31 & 1.675 & Comet \\
\hline 13 & $125^{1}$ & 19 & 19 & 29 & 33 & 2.011 & Comet \\
\hline 14 & $137^{1}$ & 16 & 19 & 27 & 29 & 1.053 & Sloughed Heap \\
\hline 15 & $137^{1}$ & 12 & 31 & 44 & 35 & 1.306 & Oval \\
\hline 16 & $137^{1}$ & 23 & 19 & 20 & 32 & 2.032 & Comet \\
\hline 17 & $137^{1}$ & 15 & 23 & 34 & 34 & 0.899 & Oval \\
\hline 18 & $137^{1}$ & 19 & 20 & 28 & 30 & 1.081 & Sloughed Heap \\
\hline 19 & 128 & 20 & 21 & 30 & 36 & 0.953 & Oval \\
\hline 20 & $138^{1}$ & 16 & 28 & 39 & 31 & 1.000 & Sloughed heap \\
\hline 21 & $138^{1}$ & 16 & 25 & 36 & 35 & 1.202 & Oval \\
\hline 22 & 117 & 11 & 7 & 16 & 12 & 2.062 & Sloughed Heap \\
\hline 23 & 94 & 16 & 26 & 35 & 36 & 0.601 & Oval \\
\hline 24 & $149^{1}$ & 14 & 30 & 41 & 36 & 0.882 & Rectangular \\
\hline 25 & $149^{1}$ & 17 & 29 & 40 & 35 & 1.140 & Oval \\
\hline 26 & $149^{1}$ & 13 & 21 & 29 & 36 & 1.036 & Rectangular \\
\hline 27 & $129^{1}$ & 12 & 9 & 13 & 16 & 1.647 & Sloughed Heap \\
\hline 28 & $129^{1}$ & 17 & 26 & 37 & 35 & 1.033 & Oval \\
\hline
\end{tabular}

In order to investigate the statistical differences among the classification data of each type, box plots of their data for each variable are shown in Figures 2-7. In the box plots, the black dot represents the mean average value within the data, the line represents the median value, the box edges represent $50 \%$ of the data between the first and third quartiles and the lines above and below the box represent the maximum and minimum values of the data.

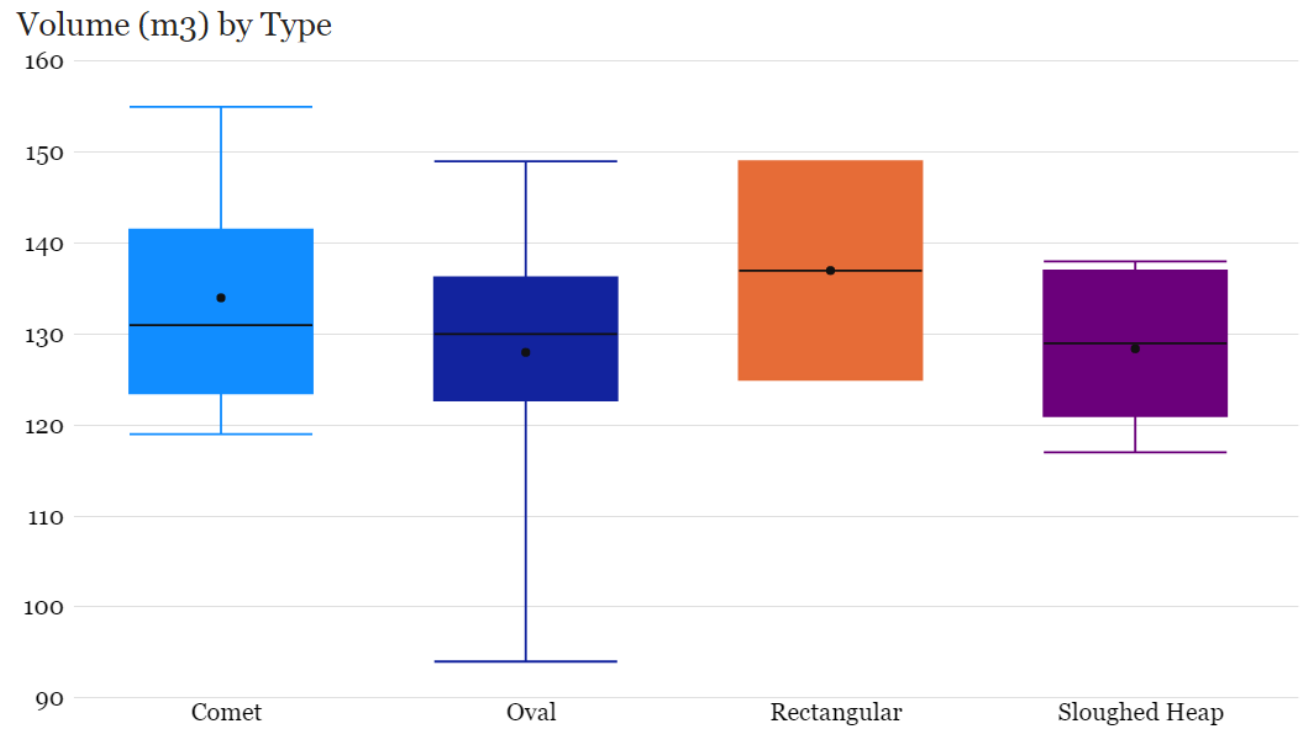

Figure 2. Box Charts of Volume $\left(\mathrm{m}^{3}\right)$ by Dump Profile Shape. 


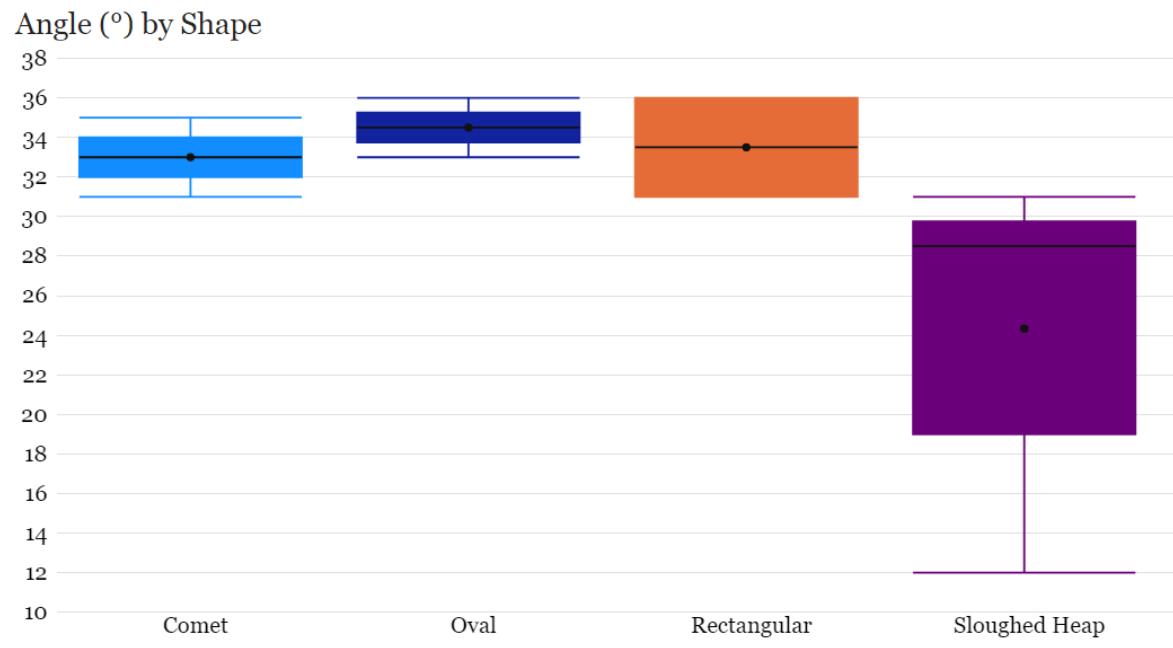

Figure 3. Box Charts of Angle $\left(^{\circ}\right)$ by Dump Profile Shape.

Max. Height (m) by Shape

35
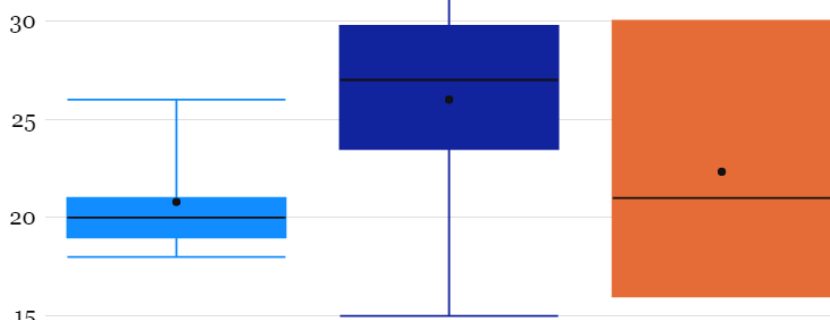

10



Oval

Rectangular
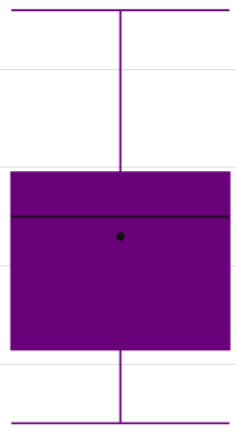

Sloughed Heap

Figure 4. Box Charts of Max. Height (m) by Dump Profile Shape.

Max. Length $(\mathrm{m})$ by Shape

50

45

40

35

30

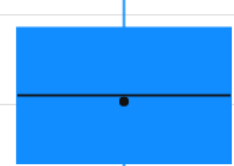

25
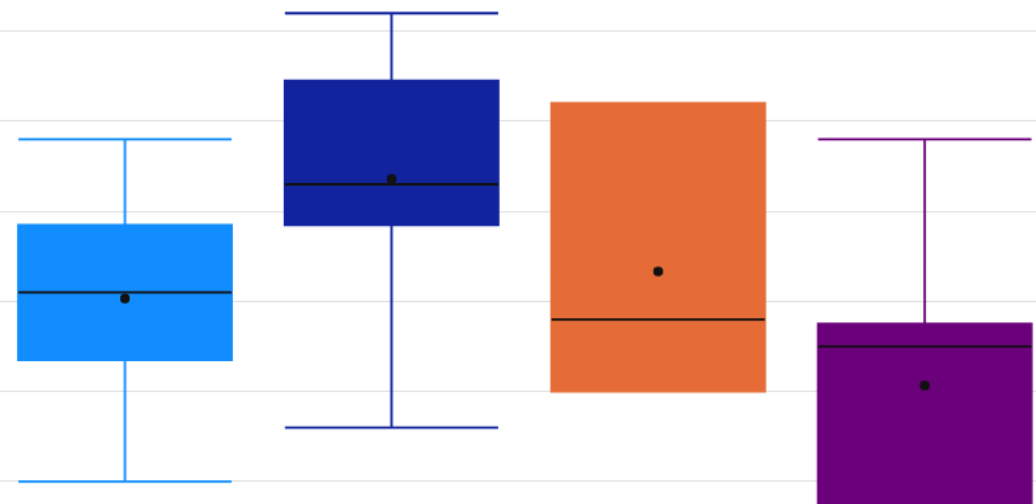

15

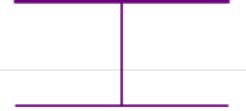

$10 \quad$ Comet

Oval

Rectangular

Sloughed Heap

Figure 5. Box Charts of Max. Length (m) by Dump Profile Shape. 




Figure 6. Box Charts of Max. Width (m) by Dump Profile Shape.

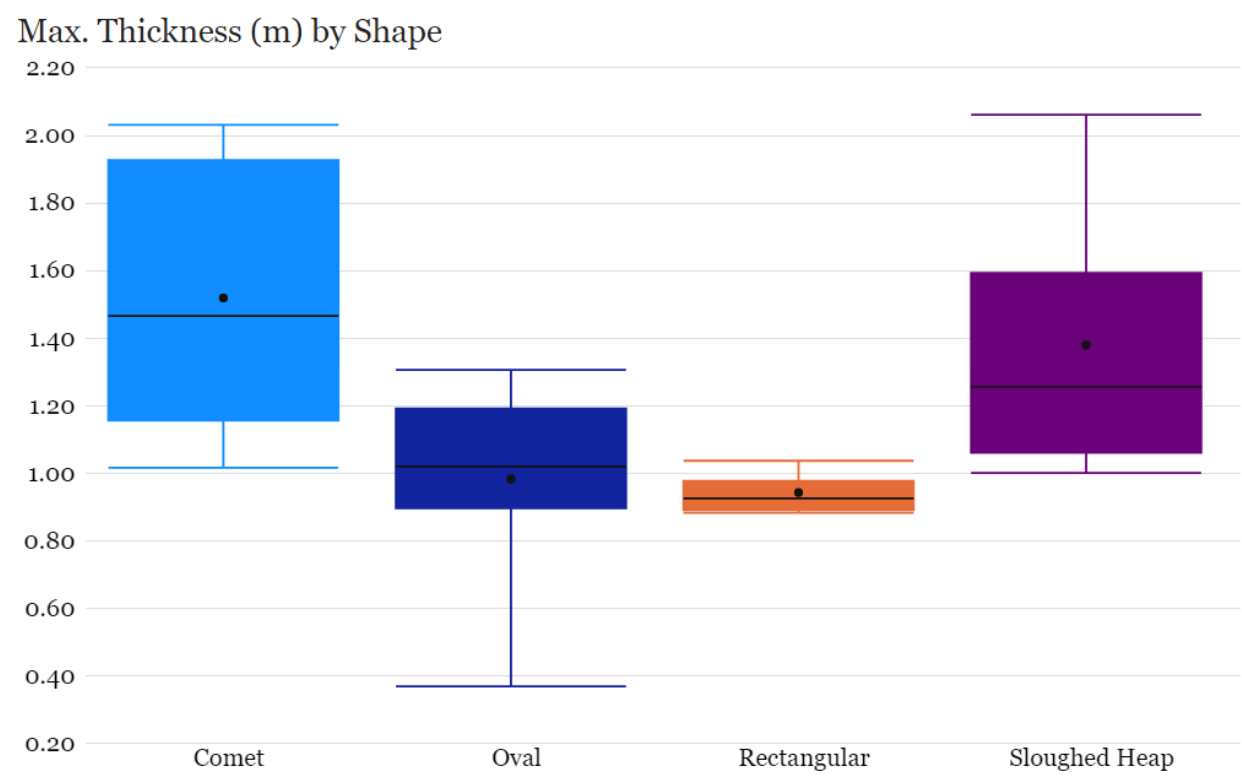

Figure 7. Box Charts of Max. Thickness (m) by Dump Profile Shape.

Figure 2 shows that the comet and rectangular dump types have a slightly higher average volume compared with the oval and sloughed heap types. Volume is influenced by how much material was loaded into the truck before dumping, and also by how much material in the dump face moved at the time of dumping. This increase in the average volume of material for the comet and rectangular dumps may be due to the fact that both dump types seem to involve the movement of additional material contained in the dump face.

Figure 3 shows a lot of similarity in the average angles of the comet, oval and rectangular dump types. Sloughed heap angles are lower because the material does not typically extend the full length of the dump face. Where the material of the sloughed heap extends along the dump face, the angle of the material matches the angles for the other dump types.

Figure 4 shows that the oval and rectangular dumps have the highest dump height. Dump height is a measurement of how much of the vertical dimension of the dump is 
covered by the dump profile. Sloughed heap and comet height values are lower because the material does not typically extend the full length of the dump face.

Figure 5 shows the same general differences between dump types as Figure 4 . This is likely due to the fact that length is a measurement of how much of the horizontal dimension of the dump is covered by the dump profile. Length values are lower for sloughed heapand comet-type dump profiles compared to the other dump types. This may be related to the same reason why height values for these types are also lower.

Figure 6 shows that comet dump profiles tend to be the widest. This may be the result of additional material from the dump face aggregating with the dump mass as it cascades, resulting in an increase in width. Rectangular dump profiles tend to have the lowest width values, which is interesting because they typically have the highest volume values, and this might be explained by a low amount of frictional resistance on the dump face compared to the cohesion of the dump mass.

As shown in Figure 7, the comet and sloughed heap dump profiles typically have a higher thickness than the oval and rectangular ones. Assuming that the dumps are of similar total volume, this is to be expected, since oval and rectangular dump profiles typically have higher height and length. Therefore, the dump material for oval and rectangular dumps is spread thinner across more surface area, which leads to less thickness. Comet dump profiles may also interact with loose material on the dump surface, and the resulting solid might include some of that material in the thickness, as it might with the total volume.

\section{Discussion}

\subsection{Modelling Discussion}

The HFMs presented in this paper offer a novel look at individual dumps. These HFMs can be used as a basis to calibrate future simulation models of dumps via the V-model for calibration described by Quist [63], Hofmann [66] and others. Figure 8 illustrates the V-model for simulation calibration and validation, which occurs over three levels. At the bottom level, validation is carried out by calibrating the individual parameters of particles in a laboratory setting. The second level involves calibration based on the aggregated behavior of the particles through multiple flow regimes. The third level compares simulated outcomes with real industrial-scale operations.

\section{Simulation Domain}

Experimental Domain



Figure 8. The V-model for DEM calibration and validation (adapted from [63]).

To the knowledge of the authors, no work has been conducted to validate dumping behavior at a real mine against simulated outcomes; however, much work has been performed to calibrate and validate ROM material simulations at lower levels of the V-model, particularly for mineral processing applications [70]. In instances such as dumping, where reality cannot be used to calibrate models, calibration involves adjusting parameters to fit HFMs instead. There is no mention of a method for creating HFMs of mine haul truck 
dumping activity in the literature. The method used for this study is easily achievable for any mine operation where UAVs and photogrammetry are presently in use.

\subsection{Dump Profile Discussion}

Even though this study found only four types of dump profiles, there may exist additional types. The factors that determine which type a dump will be categorized into are many. These factors likely fall into several categories, including the way the material is loaded into the truck, how the truck dumps the material, how the pre-existing dump face interacts with the dumped load and how the material behaves on its own. None of these factors were investigated in this paper

How the truck is loaded directly influences the volume of the resulting dump profile. It may also influence the determination of the dump profile type, forming either comet, oval or rectangular profiles. For example, if the truck is unevenly loaded with more material in the back than towards the front, this may cause the resulting dump profile to favor a comet format. However, the exact interplay between how the trucks were loaded and the resulting dump profiles remains unclear, and no information on truck loading was gathered during this study.

How the truck dumps the material clearly influences whether or not the dump profile becomes a sloughed heap or one of the other types. This is because if the truck dumps far from the crest of the dump face, it will create a sloughed heap. When the truck dumps against the crest of the dump face, the type of the resulting dump profile is either comet, oval or rectangular; however, it is unclear which one it will become from this information alone.

\subsection{Terminology Discussion}

The lack of terminology around dump profile behavior is one challenge to improving our understanding. The authors present new terminology here for the four types of dump shapes, but much more terminology is likely needed to fully describe and characterize dump profiles. This is made true by the fact that many dump profiles display characteristics of more than one type and, therefore, additional description may be required to fully classify them. For example, a sloughed heap may slough into a comet shape at the bottom of the dump, or an oval may have an extremely long rectangular section. There also needs to be reflection around how much effort should be spent creating terminology, since it is well known that the shape of mine rock piles is mainly based on topography [9].

\subsection{Practicality Discussion}

Admittedly, some findings in this study may not offer much practical applicability, especially considering the status quo of the mining industry. It is unknown whether the HFMs presented in this study represent the global characteristics of the dumping process across all mines, or whether they are limited to the mine used for the study. However, the method used for data capture was seamlessly incorporated into routine operation, and was practical from the standpoint of simplicity and ease of realization. Many mines are capable of measuring their own dump characteristics and creating HFMs for themselves. It is entirely probable that many other shapes of fallow land exist, and their discovery and classification can increase our understanding of the cascading process of ROM material.

Additionally, as has been previously stated, the findings of this study are practical for the purpose of verifying the accuracy of the simulation modelling of individual truck end dumps. Without an HFM to verify simulations against, there would be less confidence in the accuracy and relevance of the simulation. It is computationally intensive to simulate an entire dump area. Simulating individual dumps may allow for larger areas to be simulated with less computational power through the use of pseudo-particles [4].

Dumps generally conform to whatever shape the local topography provides, but knowledge of the common shapes provided via a routine dumping process for a particular ore at a given mine has historically been mostly speculatory. Speculation of this kind causes engineers and mine planners to place an unknown amount of dependance on operators 
that work with the material constantly to ensure the process is conforming to plan. In future autonomous mining scenarios, this dependance will not be allowed. Thus, digitally transforming the dumping process is hypothesized to support continuity in the transition towards autonomous mining. Without operators at the helm, there is little knowledge to ensure that dumping is occurring correctly. Additionally, without a basic reference, there would be no way to determine the performance quality of the autonomous equipment. The fact that autonomous equipment will be covered in sensors to map the work area continuously will mean very little, unless it is known what conformity should actually looks like.

As another hypothesis, there might be a relationship of practical synergy between predictive modelling and UAV surveys. UAV surveys have become increasingly ubiquitous at mines, and can accomplish tasks to a level of quality unachievable by traditional survey crews within a greatly reduced timeframe. They could be made to occur at such frequent intervals as to overwhelm mining engineers and long-range planners. The HFMs described in this article demonstrate the parameterization of the dumping process, which could facilitate the training and validation of predictive models to help automate design conformity to UAV surveys of rock piles, thereby decreasing the cognitive load placed on the domain experts.

\section{Conclusions}

HFMs of dump profiles for 28 dumps were created. These HFMs show characteristic behaviors classifiable into four types, named comet, oval, rectangular and sloughed heap. These classifications may make it easier to examine the dumping process as a whole. While more terminology and modelling will be required to gain a complete understanding of the dumping process, the HFMs examined here provide a basis to articulate new terminology and calibrate new modelling.

Since further investigation is required, some recommendations for future study in this area include:

- Investigate factors that determine the classification of a given dump profile;

- Isolate additional variables that influence the cascading behavior of ROM from haul trucks;

- Simulate and calibrate particle modelling using HFMs;

- Validate and test the ability to accurately simulate and predict the dump characteristics beforehand;

- Correct for the difference between GPS coordinates recorded as dump locations and the true centroid coordinates of the dumped material;

- Develop constraints and map FMS data to rock piles;

- Prove the accuracy of these mapping/modelling techniques through a robust sampling campaign;

- Adapt this or a similar method for dozers and other equipment that frequently handle material at dumps and stockpiles;

- Review and analyze correlated phenomena (bulk phenomena in heap leaches, stratification, slope stability, etc.);

- Incorporate simulated predictions into a larger mine-to-mill optimization model.

Supplementary Materials: The dump geometries can be downloaded at: https://zenodo.org/ record/5789951\#.YgQiqJbMKUl.

Author Contributions: Conceptualization, A.Y.; Data curation, A.Y.; Formal analysis, A.Y.; Funding acquisition, W.P.R.; Investigation, A.Y.; Methodology, A.Y.; Project administration, W.P.R.; Resources, W.P.R.; Software, A.Y.; Supervision, W.P.R. All authors have read and agreed to the published version of the manuscript.

Funding: This research received no external funding.

Data Availability Statement: Data supporting the reported results can be found via the link in the Supplementary Materials. 
Conflicts of Interest: The authors declare no conflict of interest.

\section{References}

1. Erkayaoglu, M.; Dessureault, S. Improving mine-to-mill by data warehousing and data mining. Int. J. Min. Reclam. Environ. 2019, 33, 409-424. [CrossRef]

2. Adel, G.; Kojovic, T.; Thornton, D. Mine-to-Mill Optimization of Aggregate Production; Virginia Polytechnic Inst. and State Univ.(Virginia Tech), Blacksburg: Virginia, VA, USA, 2006.

3. Valery, W.; Duffy, K.; Jankovic, A. Mine to Mill Optimization. In SME Mineral Processing and Extractive Metallurgy Handbook; Kawatara, K., Young, C.A., Eds.; Society for Mining, Metallurgy, and Exploration (SME): Englewood, CO, USA, 2019; pp. 335-343.

4. Servin, M.; Vesterlund, F.; Wallin, E. Digital Twins with Distributed Particle Simulation for Mine-to-Mill Material Tracking. Minerals 2021, 11, 524. [CrossRef]

5. Holmberg, K.; Kivikytö-Reponen, P.; Härkisaari, P.; Valtonen, K.; Erdemir, A. Global energy consumption due to friction and wear in the mining industry. Tribol. Int. 2017, 115, 116-139. [CrossRef]

6. Hartman, H.L.; Mutmansky, J.M. Introductory Mining Engineering; John Wiley \& Sons: Hoboken, NJ, USA, 2002.

7. Young, A.; Rogers, W.P. Modelling Large Heaped Fill Stockpiles Using FMS Data. Minerals 2021, 11, 636. [CrossRef]

8. McLemore, V.T.; Fakhimi, A.; van Zyl, D.; Ayakwah, G.F.; Anim, K.; Boakye, K.; Ennin, F.; Felli, P.; Fredlund, D.; Gutierrez, L.A.F.; et al. Literature Review of Other Rock Piles: Characterization, Weathering, and Stability; Questa Rock Pile Weathering Stability Project; New Mexico Bureau of Geology and Mineral Resources: Socorro, NM, USA, 2009.

9. Zahl, E.G.; Biggs, F.; Boldt, C.M.K.; Connolly, R.E.; Gertsch, L.; Lambeth, R.H.; Stewart, B.M.; Vickery, J.D. Waste Disposal and Contaminant Control. In SME Mining Engineering Handbook; Darling, P., Ed.; Society for Mining, Metallurgy and Exploration Inc.: Littleton, CO, USA, 1992; pp. 1170-1180.

10. Siddiqui, F.; Shah, S.; Behan, M. Measurement of Size Distribution of Blasted Rock Using Digital Image Processing. J. King Abdulaziz Univ. Eng. Sci. 2009, 20, 81-93. [CrossRef]

11. Badroddin, M.; Bakhtavar, E.; Khoshrou, H.; Rezaei, B. Efficiency of standardized image processing in the fragmentation prediction in the case of Sungun open-pit mine. Arab. J. Geosci. 2013, 6, 3319-3329. [CrossRef]

12. Maerz, N.H. Online Fragmentation Analysis: Achievements in the Mining Industry. In Proceedings of the 7th Annual ICAR Symposium, Austin, TX, USA, 19-21 April 1999.

13. Bao, Y.; Han, X.; Chen, J.; Zhang, W.; Zhan, J.; Sun, X.; Chen, M. Numerical assessment of failure potential of a large mine waste dump in Panzhihua City, China. Eng. Geol. 2019, 253, 171-183. [CrossRef]

14. Poulsen, B.; Khanal, M.; Rao, A.M.; Adhikary, D.; Balusu, R. Mine overburden dump failure: A case study. Geotech. Geol. Eng. 2014, 32, 297-309. [CrossRef]

15. Mhaske, S.; Kapoor, I.; Pathak, K.; Kayet, N. Slope Stability Analysis of the Overburden Dump of Meghahatuburu Iron Ore Mines in Singhbhum Region of India. In Proceedings of the International Field Exploration and Development Conference 2019, Xi'an, China, 16-18 October 2019; Springer: Singapore, 2020.

16. McCoy, J.T.; Auret, L. Machine learning applications in minerals processing: A review. Miner. Eng. 2019, 132, 95-109. [CrossRef]

17. Bartos, P.J. Is mining a high-tech industry? Investigations into innovation and productivity advance. Resour. Policy 2007, 32, 149-158. [CrossRef]

18. Sánchez, F.; Hartlieb, P. Innovation in the mining industry: Technological trends and a case study of the challenges of disruptive innovation. Min. Metall. Explor. 2020, 37, 1385-1399. [CrossRef]

19. Hustrulid, W.A.; Kuchta, M.; Martin, R.K. Open Pit Mine Planning and Design, Two Volume Set E CD-ROM Pack, [CD-ROM]; CRC Press: Leiden, The Netherlands, 2013.

20. Casey, J. AngloGold Ashanti Provides Obuasi Wnderground Mining Update. Basic Materials \& Resources Monitor Worldwide (Amman, Jordan). 2021. Available online: https:/ / www.globalminingreview.com/mining/30092021/anglogold-ashantiprovides-obuasi-underground-mining-update/ (accessed on 28 January 2022).

21. Kamoa-Kakula Copper Project Mines and Stockpiles 269,000 Tonnes of Ore from the Kakula and Kansoko Mines in December, at an Average Grade of 5.36\% Copper, Including 55,000 Tonnes Grading 8.75\% Copper from the High-Grade Centre of the Kakula Mine, in ENP Newswire. 2021. Available online: https:/ /link.gale.com/apps/doc/A647556674/ITOF?u=marriottlibrary\&sid= bookmark-ITOF\&xid=71f68e94 / (accessed on 26 January 2022).

22. Yannopoulos, J.C. Leaching Low-Grade Gold Ores. In The Extractive Metallurgy of Gold; Springer: Boston, MA, USA, $1991 ;$ pp. 115-136.

23. Yi, R. Optimum determination of sub-grade stockpiles in open pit mines. AUSIMM 1988, 4, 57-62.

24. Investigators at Colorado School of Mines Detail Findings in Operations Research (Practical Performance of an Open Pit Mine Scheduling Model Considering Blending and Stockpiling). Computer Weekly News. 2020, p. 285. Available online: https://link. gale.com/apps/doc/A619469258/ITOF?u=marriottlibrary\&sid=bookmark-ITOF\&xid=73be3380 (accessed on 26 January 2022).

25. Arnoldi, M. AfriTin Suspends Mining in Namibia, Continues Processing. 2020. Available online: https:/ / www.engineeringnews. co.za/article/afritin-suspends-mining-in-namibia-continues-processing-2020-03-31 (accessed on 26 January 2022).

26. Dutta, S. Record 132 Million Tonne Coal Stockpiles Cast Shadow over New Mines. 2021. Available online: https: / / timesofindia.indiatimes.com/business/india-business/record-132-million-tonne-coal-stockpiles-cast-shadow-over-newmines/articleshow / 81973823.cms (accessed on 26 January 2022). 
27. Arnoldi, M. ARMs Iron-Ore Mines Allowed to Continue Loading from Stockpile. 2020. Available online: https://www.miningweekly. com/article/arms-iron-ore-mines-allowed-to-continue-loading-from-stockpile-2020-04-03 (accessed on 26 January 2022).

28. Lundin Gold Inc. Lundin Gold Restarts Operations at Fruta Del Norte and Provides 2020 Outlook. 2020. Available online: https:/ / www.newswire.ca/news-releases/lundin-gold-restarts-operations-at-fruta-del-norte-and-provides-2020-outlook832174232.html (accessed on 26 January 2022).

29. Legal Monitor Worldwide. Endeavour Silver Resumes Operations at Three Mexico Mines. 2020. Available online: https:/ /link.gale. com/apps/doc/A625237491/ITOF?u=marriottlibrary\&sid=bookmark-ITOF\&xid=703ae665 (accessed on 26 January 2022).

30. Legal Monitor Worldwide. Lundin Mining Announces Resumption of Full Production Rates at Chapada Mine. 2020. Available online: https:/ /link.gale.com/apps/doc/A646443468/ITOF?u=marriottlibrary\&sid=bookmark-ITOF\&xid=d2753530 (accessed on 26 January 2022).

31. Basic Materials \& Resources Monitor Worldwide (Amman, Jordan). Endeavour Expects Mining Activities to Resume at Boungou in The Coming Weeks. 2020. Available online: https://link.gale.com/apps/doc/A634219247/ITOF?u=marriottlibrary\&sid= bookmark-ITOF\&xid=2681c7ac (accessed on 26 January 2022).

32. Basic Materials \& Resources Monitor Worldwide (Amman, Jordan). Trevali Provides Update on Extension of Government Declaration of National Emergency in Peru. 2020. Available online: https://link.gale.com/apps/doc/A618915153/ITOF?u= marriottlibrary\&sid=bookmark-ITOF\&xid=05ffadcf (accessed on 26 January 2022).

33. Plus Company Updates. Gold Resource Corporation's Don David Gold Mine Begins Process of Ramping up Activities, Update's 2021 Guidance. 2021. Available online: https://link.gale.com/apps/doc/A674749128/ITOF?u=marriottlibrary\&sid=bookmarkITOF\&xid=2e950161 (accessed on 26 January 2022).

34. Legal Monitor Worldwide. Metro Mining Delays Bauxite Hills Expansion Amid Market Uncertainties. 2020. Available online: https:/ /link.gale.com/apps/doc/A624952426/ITOF?u=marriottlibrary\&sid=bookmark-ITOF\&xid=52e3f3cc (accessed on 26 January 2022).

35. Carter, R.A. Staying on Top of Stockpile Management. Eng. Min. J. 2018, 219, 58.

36. Legal Monitor Worldwide. Clever Solutions, Right Equipment Saves Re-mining Project. 2021. Available online: https://link.gale. com/apps/doc/A668313798/ITOF?u=marriottlibrary\&sid=bookmark-ITOF\&xid=9dae0354 (accessed on 26 January 2022).

37. M \& A Navigator. Deal Snapshot: Trident Resources Acquires Copper Royalty for USD 5m. 2020. Available online: https: / /ink.gale. com/apps/doc/A627983091/ITOF?u=marriottlibrary\&sid=bookmark-ITOF\&xid=019a144b (accessed on 26 January 2022).

38. Legal Monitor Worldwide. Prospect Mining Studio Selects Startups to Pilot Sustainability Solutions. 2021. Available online: https:/ / link.gale.com/apps/doc/A671464583/ITOF?u=marriottlibrary\&sid=bookmark-ITOF\&xid=c5bd619a (accessed on 26 January 2022).

39. Braun, R.L.; Lewis, A.E.; Wadsworth, M.E. In-place leaching of primary sulfide ores: Laboratory leaching data and kinetics model. Metall. Trans. 1974, 5, 1717-1726. [CrossRef]

40. Bartlett, R.W. Simulation of ore heap leaching using deterministic models. Hydrometallurgy 1992, 29, 231-260. [CrossRef]

41. Davis, G.B.; Ritchie, A.I.M. A model of oxidation in pyritic mine wastes: Part 1 equations and approximate solution. Appl. Math. Model. 1986, 10, 314-322. [CrossRef]

42. Ghorbani, Y.; Becker, M.; Mainza, A.; Franzidis, J.-P.; Petersen, J. Large particle effects in chemical/biochemical heap leach processes-A review. Miner. Eng. 2011, 24, 1172-1184. [CrossRef]

43. Wang, L.; Yin, S.; Deng, B. Understanding the Effect of Stepwise Irrigation on Liquid Holdup and Hysteresis Behavior of Unsaturated Ore Heap. Minerals 2021, 11, 1180. [CrossRef]

44. Lizama, H.M. How copper dump leaching works. Miner. Eng. 2021, 171, 107075. [CrossRef]

45. Van Staden, P.J.; Petersen, J. The effects of simulated stacking phenomena on the percolation leaching of crushed ore, Part 2: Stratification. Miner. Eng. 2019, 131, 216-229. [CrossRef]

46. Benito, J.G.; Ippolito, I.; Vidales, A.M. Novel aspects on the segregation in quasi 2D piles. Powder Technol. 2013, $234,123-131$. [CrossRef]

47. Zhang, S.; Liu, W. Application of aerial image analysis for assessing particle size segregation in dump leaching. Hydrometallurgy 2017, 171, 99-105. [CrossRef]

48. Plus Company Updates. Cobalt Blue Holdings Limited: COB Executes MOU with State of Queensland: Recovery of Cobalt from Mine Waste. 2021. Available online: https://link.gale.com/apps/doc/A687700113/ITOF?u=marriottlibrary\&sid=bookmarkITOF\&xid=99e7db65 (accessed on 26 January 2022).

49. Basic Materials \& Resources Monitor Worldwide (Amman, Jordan). Prairie River Minerals and NRRI Pilot Scram Mining Operation. 2021. Available online: https://link.gale.com/apps/doc/A674990833/ITOF?u=marriottlibrary\&sid=bookmarkITOF\&xid=25ea5faa (accessed on 26 January 2022).

50. Mena Report. Australia: Territory Iron Shipment Leaves Darwin Port. 2021. Available online: https://link.gale.com/apps/doc/ A666537309/ITOF?u=marriottlibrary\&sid=bookmark-ITOF\&xid=f12334b3 (accessed on 26 January 2022).

51. Plus Company Updates. Red River Resources Limited: Red River Announces Maiden Gold Resource for Hillgrove Stockpile. 2020. Available online: https://link.gale.com/apps/doc/A617069866/ITOF?u=marriottlibrary\&sid=bookmark-ITOF\&xid=ee3db896 (accessed on 26 January 2022). 
52. ENP Newswire. Equus Mining Limited-High Grade Pegaso Drill Results Confirm Potential of Mineralisation along Trend from Historic Mines. 2021. Available online: https://link.gale.com/apps/doc/A662116991/ITOF?u=marriottlibrary\&sid=bookmarkITOF\&xid=0c36356d (accessed on 26 January 2022).

53. Plus Company Updates. Elim Mining Announces $\$ 140$ Million Cumulative Free Cash Flow from the Cactus Mine Stockpile Preliminary Economic Assessment. 2020. Available online: https://link.gale.com/apps/doc/A617122264/ITOF?u=marriottlibrary\& sid=bookmark-ITOF\&xid=bcc4ef16 (accessed on 26 January 2022).

54. ENP Newswire. Providence Gold Drilling Stockpile. 2020. Available online: https://link.gale.com/apps/doc/A642311201 /ITOF?u=marriottlibrary\&sid=bookmark-ITOF\&xid=9dd90cde (accessed on 26 January 2022).

55. ENP Newswire. Southern Empire Provides Oro Cruz Project Historical Mine Dumps Assay Results and Preliminary Cyanidation Metallurgical Test Results. 2021. Available online: https://link.gale.com/apps/doc/A666663259/ITOF?u=marriottlibrary\&sid= bookmark-ITOF\&xid=c7fe179b (accessed on 26 January 2022).

56. Legal Monitor Worldwide. Eclipse Metals Targets Mining Licence to Breathe New Life into Historic Ivittuut Cryolite Mine. 2021. Available online: https:/ /link.gale.com/apps/doc/A666122579/ITOF?u=marriottlibrary\&sid=bookmark-ITOF\&xid=70d6d24a (accessed on 26 January 2022).

57. Young, A.; Rogers, P. A review of digital transformation in mining. Min. Metall. Explor. 2019, 36, 683-699. [CrossRef]

58. Vial, G. Understanding digital transformation: A review and a research agenda. J. Strateg. Inf. Syst. 2019, 28, 118-144. [CrossRef]

59. Hinings, B.; Gegenhuber, T.; Greenwood, R. Digital innovation and transformation: An institutional perspective. Inf. Organ. 2018, 28, 52-61. [CrossRef]

60. Job, A.; McAree, P.R. Three Case Studies on the Implementation of New Technology in the Mining Industry. In Proceedings of the Iron Ore Conference, Perth, Australia, 24-26 July 2017.

61. Chaulya, S.; Prasad, G.M. Sensing and Monitoring Technologies for Mines and Hazardous Areas: Monitoring and Prediction Technologies; Elsevier: Amsterdam, The Netherlands, 2016.

62. Francioni, M.; Salvini, R.; Stead, D.; Giovannini, R.; Riccucci, S.; Vanneschi, C.; Gullì, D. An integrated remote sensing-GIS approach for the analysis of an open pit in the Carrara marble district, Italy: Slope stability assessment through kinematic and numerical methods. Comput. Geotech. 2015, 67, 46-63. [CrossRef]

63. Johannes Quist, M.E. Framework for DEM Model Calibration and Validation. In Proceedings of the 14th European Symposium on Comminution and Classification, Gothenburg, Sweden, 7-10 September 2015.

64. Durst, P.J.; Goodin, C. High fidelity modelling and simulation of inertial sensors commonly used by autonomous mobile robots. World J. Model. Simul. 2012, 8, 172-184.

65. George, A.D.; VanLoon, R.A. High-Fidelity Modelling and Simulation of Myrinet System Area Networks. Int. J. Model. Simul. 2001, 21, 40-50. [CrossRef]

66. Hofmann, M. On the Complexity of Parameter Calibration in Simulation Models. J. Def. Model. Simul. 2005, 2, 217-226. [CrossRef]

67. Vermeer, W.; Hjorth, A.; Jenness, S.M.; Brown, C.H.; Wilensky, U. Leveraging Modularity During Replication of High-Fidelity Models: Lessons from Replicating an Agent-Based Model for HIV Prevention. J. Artif. Soc. Soc. Simul. 2020, 23, 7. [CrossRef]

68. Zhao, S. 3D Real-Time Stockpile Mapping and Modelling with Accurate Quality Calculation Using Voxels. Ph.D. Thesis, University of Adelaide, Adelaide, Australia, 2016.

69. Siqueira, H.L.; Marcato, J.; Matsubara, E.; Eltner, A.; Colares, R.A.; Santos, F.M. The Impact of Ground Control Point Quantity on Area and Volume Measurements with UAV SFM Photogrammetry Applied in Open Pit Mines. In Proceedings of the 2019 IEEE International Geoscience and Remote Sensing Symposium (IGARSS), Yokohama, Japan, 28 July-2 August 2019.

70. Tavares, L.M. A review of advanced ball mill modelling. KONA Powder Part. J. 2017, 34, 106-124. [CrossRef] 